\title{
Pain Management
}

Editors

PERRY G. FINE

MICHAEL A. ASHBURN

\section{ANESTHESIOLOGY CLINICS}

www.anesthesiology.theclinics.com

Consulting Editor

LEE A. FLEISHER

June 2016 • Volume 34 • Number 2 